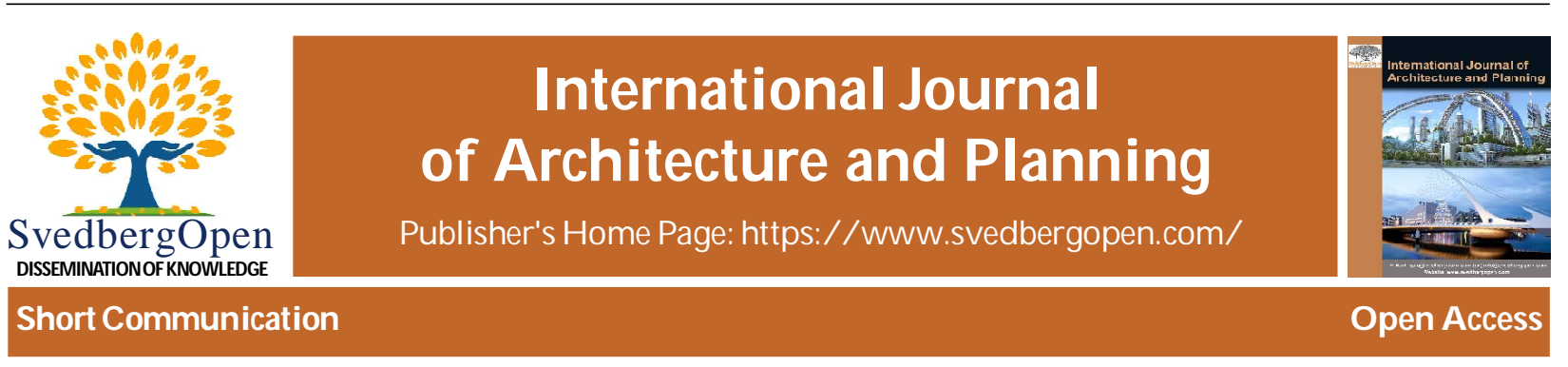

\title{
Cultural Context in Architecture
}

\section{Saurav Koirala ${ }^{1 *}$}

${ }^{1}$ Second Year First Part, Bachelor's Degree in Architecture, IOE Thapathali Campus, Kathmandu. E-mail: koiralas874@gmail.com

\begin{tabular}{|c|c|}
\hline Article Info & $\begin{array}{l}\text { Abstract } \\
\text { Architecture is manifestation and expression of culture. So, architecture and culture are } \\
\text { interdependent and inseparable. In this report I will try to find answer of question like; }\end{array}$ \\
\hline $\begin{array}{l}\text { Volume 1, Issue 2, September } 2021 \\
\text { Received : } 18 \text { January } 2021\end{array}$ & $\begin{array}{l}\text { What is concept of culture? And how architectural form, shape and style are influenced by } \\
\text { cultural values and norms? }\end{array}$ \\
\hline Accepted : 25 July 2021 & Keywords: Architecture, Art, Culture, Human, Society, Identity, Value, Tradition, Context \\
\hline $\begin{array}{l}\text { Published : } 05 \text { September } 2021 \\
\text { doi: 10.51483/IJARP.1.2.2021.23-27 }\end{array}$ & $\begin{array}{l}\text { (C) } 2021 \text { Saurav Koirala. This is an open access article under the CC BY license } \\
\text { (https://creativecommons.org/licenses/by/4.0/), which permits unrestricted use, distribution, } \\
\text { and reproduction in any medium, provided you give appropriate credit to the original author(s) } \\
\text { and the source, provide a link to the Creative Commons license, and indicate if changes were made. }\end{array}$ \\
\hline
\end{tabular}

\section{Introduction}

"Architecture is the art, which combines expression, technology and the satisfaction of human needs. Its purpose is to make places where people feel more human, more alive and more satisfied. With respect to vitruvius words, architecture is the art which combines Utilitas, Firmitas and Venustas or human behavior, technology and beauty." (Moore, n.d)

It has been recognized that, Architecture is influenced by many factors like, social, physical, cultural, environmental, economic and political, etc. But do we really pay serious attention to balance such factors for good design affecting in human comfort?

Architecture is always followed by certain rules and regulation and it has strong bond with culture, values and behavior of society. Society is the product of culture and human beings are the inhabitants of society. So, human beings always express himself social and cultural. Architecture is an aesthetic art of creating essential habitable space for human beings. "Architecture is a profession rooted in culture" (Rapoport, 1969). Architecture is manifestation and expression of culture. So, architecture and culture are interdependent and inseparable.

In this paper, I will try my best for defining the concept of culture first of all. Then, I will find how architecture is related with culture? And how architectural form, shape, style and technique are influenced by cultural values and norms?

\section{Concept of Culture}

Culture is everything that people have, think, perceive, know, feel, and do as members of society. "Culture is the material and non-material works of arts and science, plus the knowledge; manners; education, made of thought; behavior and attitude accumulated by people through their history." (Ahianba, 2009) I use 'The Encyclopaedia of Philosophy' definition

\footnotetext{
* Corresponding author: Saurav Koirala, Second Year First Part, Bachelor's Degree in Architecture, IOE Thapathali Campus, Kathmandu.E-mail: koiralas874@gmail.com
} 
which reads, "The whole way of life, material, intellectual, and spiritual, of a given society" (Edwards, 1967). Similarly, Webster's New International Dictionary defines culture as "The complex of distinctive attainments, beliefs, traditions [which constitute] the background of racial, religious, or social group" (Neilson, 1941). Also, The Oxford Advanced Learners' Dictionary defines culture as, "The customs and beliefs, art, way of life and social organization of a particular country or group" (Joanna, 2014). In simple, Culture is way of life defined by norms and values.

"Culture is the framework of beliefs, expressive symbols and values in terms of which individuals define their feelings and make their judgments" (Geertz, 1957).

Culture is the ritual practice of society from ancient/traditional periods. Culture is practiced through the group of people who occupy a specific locality and who share the same cultural traditions. A distinct and relatively autonomous community whose member's mutual social relations are embedded in and expressed through the culture. In the context of rural and urban areas, Culture is the main factors which can differentiate them. The dimensions and characteristics of culture were presented in Table 1.

\begin{tabular}{|l|l|}
\hline Table 1: Dimensions and Characteristics of Culture \\
\hline Dimensions of Cultures & Characteristics of Cultures \\
\hline Values & Culture is Learned \\
\hline Norms & Culture is Unconscious \\
\hline Ideas/Beliefs & Culture is Shared \\
\hline Attitudes & Culture is Integrated \\
\hline Symbols & Culture is Symbolic \\
\hline Traditions & Culture is Way of Life \\
\hline Artifacts & Culture is Dynamic Culture is Relative \\
\hline
\end{tabular}

Source: From the Collection of Author

"Culture is about the intellectual, social and spiritual development and exhibiting it as a trait of a specific people. Culture is the history of a people's past and present and it goes further to presenting anticipated picture of events for the future. The culture of a people evolves overtime thereby changing from one type of civilization to another" (Ahianba, 2009).

A good knowledge of any culture can help open up new frontiers for unlimited development. Any incident, invention or social activity extensively used or enjoyed eventually becomes a cultural norm as opposed to the primary purpose of its occurrence.

\section{Culture and Architecutre}

Architecture is the manifestation and expression of culture. So, architecture and culture are interdependent and inseparable. Architecture is the part of identity of each community and carries the message of culture of that society. Therefore, architecture depends upon the geography, cultures, traditions, manners and knowledge of the community as well as its history. The form and relationships of buildings and spaces acts as a kind of 'cultural marker', which can describe the way of life and social status of its inhabitants. There is no doubt that architecture and layout of buildings, and their interior and exterior facades are among the manifestations of civilization and culture of each community. The physical features of architecture such as shape, size, decorations, and constructions style, etc. are practiced through the cultural system of society.

Architecture is the results of dynamic thought of creating space influenced by factors like beauty, knowledge and design. It can be said that, the space defined by architecture is stable or not is defined by the needs of today's society or Culture of inhabitants of that society. Culture is the product of experience from past time to present time.

\section{Characteristics of Culture in Architecutre}

Creating space in architecture appears easy but in fact it is very complex and difficult in deep. It is proven that people are affected by the environment. Human beings cannot adjust in natural environment and hence, they build and organizes 
artificial environment where they can live in. Types of architectural spaces have changed many times through the history. Culture have both sustainable and dynamic aspects with respect to time. If culture had only stable status, Architecture would have been consistent continuation throughout the history. But, nature of human and culture of his society had been changed in each and every generation. Therefore, the characteristics of shapes, forms and spaces defined by architecture is difference and awesome in each period and generations. The changes in architecture is generally influenced by culture of that period. The main characteristics of culture in architecture were shown in Chart 1.

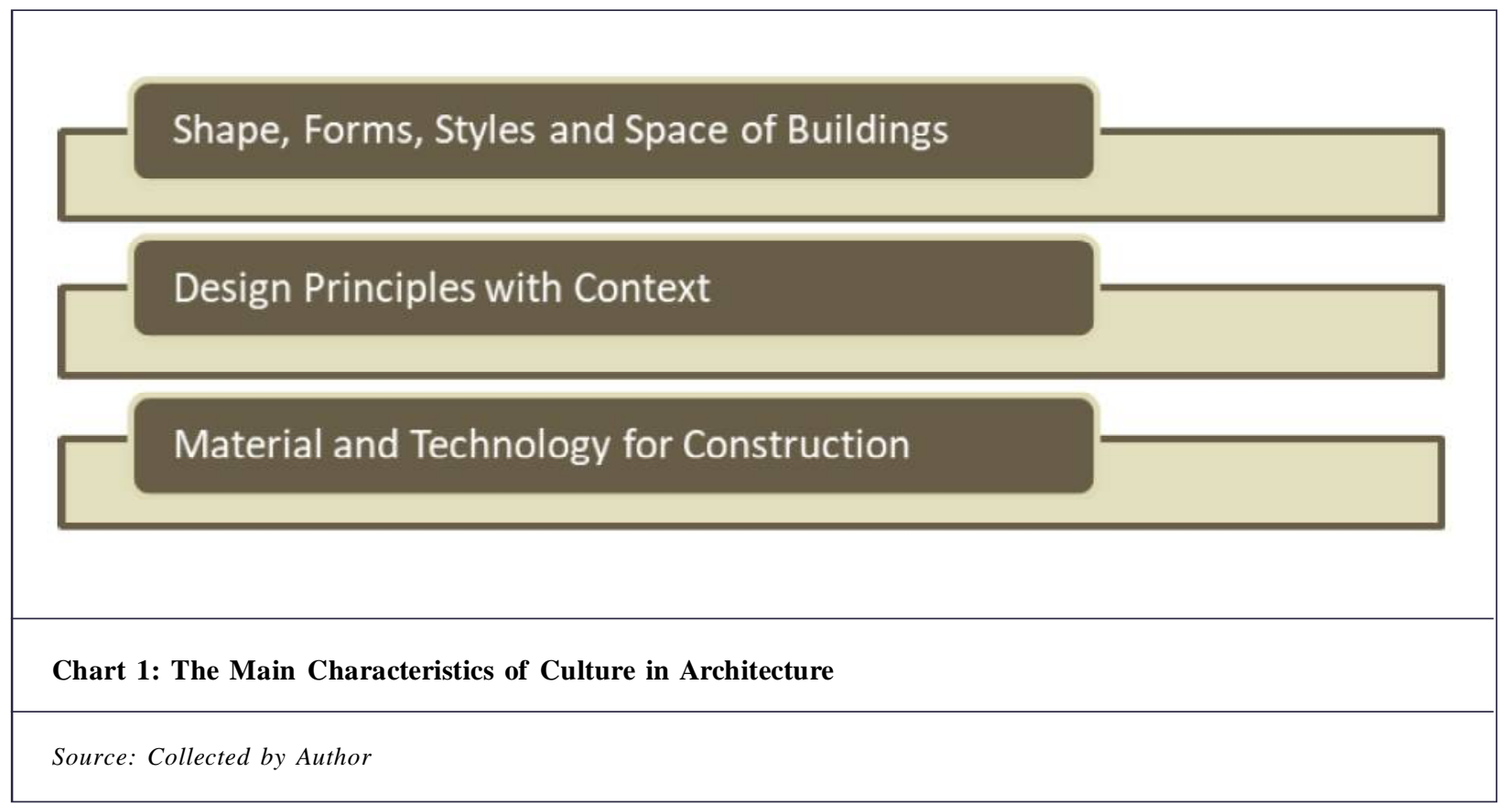

Shapes, forms, styles and spaces are main factors in architectural design process. These are influenced by the cultural values of society. In religious context, there are different forms, shapes and styles with respect to different religion. For example; In Hindu religion, the architecture style of temple is like Shikhara, Sattala and Pagoda, etc.; In Buddhist religion, the architecture style are Stupas, Chaityas and Vihara, etc.; In Muslim religion, the architectural style are Masjid, Gothic, etc.; In Christian religion, Church architecture is main style. Hence, different architectural styles are existed only due to the various cultural system are being practiced in society.

In Hindu religion of Indian sub-continent, different design principal are practicing. Design guidelines with respect to Vaastupurushmandala is called 'Vaastushastra' is strongly followed. This is only due to the cultural norms and values. In China, Chinese are following the design process with respect to 'Feng Sui' and 'Chi', i.e., Magnetic Field and Sun Light. In ancient time, Egyptian believed in the life after death, so, they have designed the architectural form considering life after death. Hence, there are different design principles for creating space are only due to the difference in culture and identity of society.

The use of technology and materials in different cultural practices are also various. In Egyptian period the material used for construction are only big stone. But, in Roman period, Roman used concrete and cement for construction. In Vedic period, Hindu used timber, bamboo, stone and mud for construction work. There are various construction process and material used in various period and time in the history and now. Hence, material and technology used are also influenced by cultural practice in the human society.

\section{Cultuaral Practices in Nepalese Architecture}

Nepalese architecture has its own history. From the historical background of Nepal, many dynasties ruled over Nepal in different time. Kirati Dynasty, Soma Dynasty, Lichhavi Dynasty, Malla Dynasty, Shah Dynasty, Rana Dynasty and Modern Nepal are the different powerful and importance rulers in Nepal. In different dynasty, there was different culture were practiced. And the architectural pieces of that different periods are various to each other. It is due to different Cultural values and beliefs. Ashoka stupa, Kailashkuta, Changu Narayan, Durbar squares, Gorkha Durbar and Nuwakot Durbar, neo-classical style, and modern architecture are some example of architectural work of different times of Nepal. They all are different to each other with respect to form, shape, style and created space in the architectural 
values. The construction technology and material used in these architectural pieces are also different. These differences were due to the various cultural practices and ritual beliefs. Hence, architecture is influenced by cultural values and norms in every works and every periods. Nepalese architecture could be best example for cultural influences in architecture.
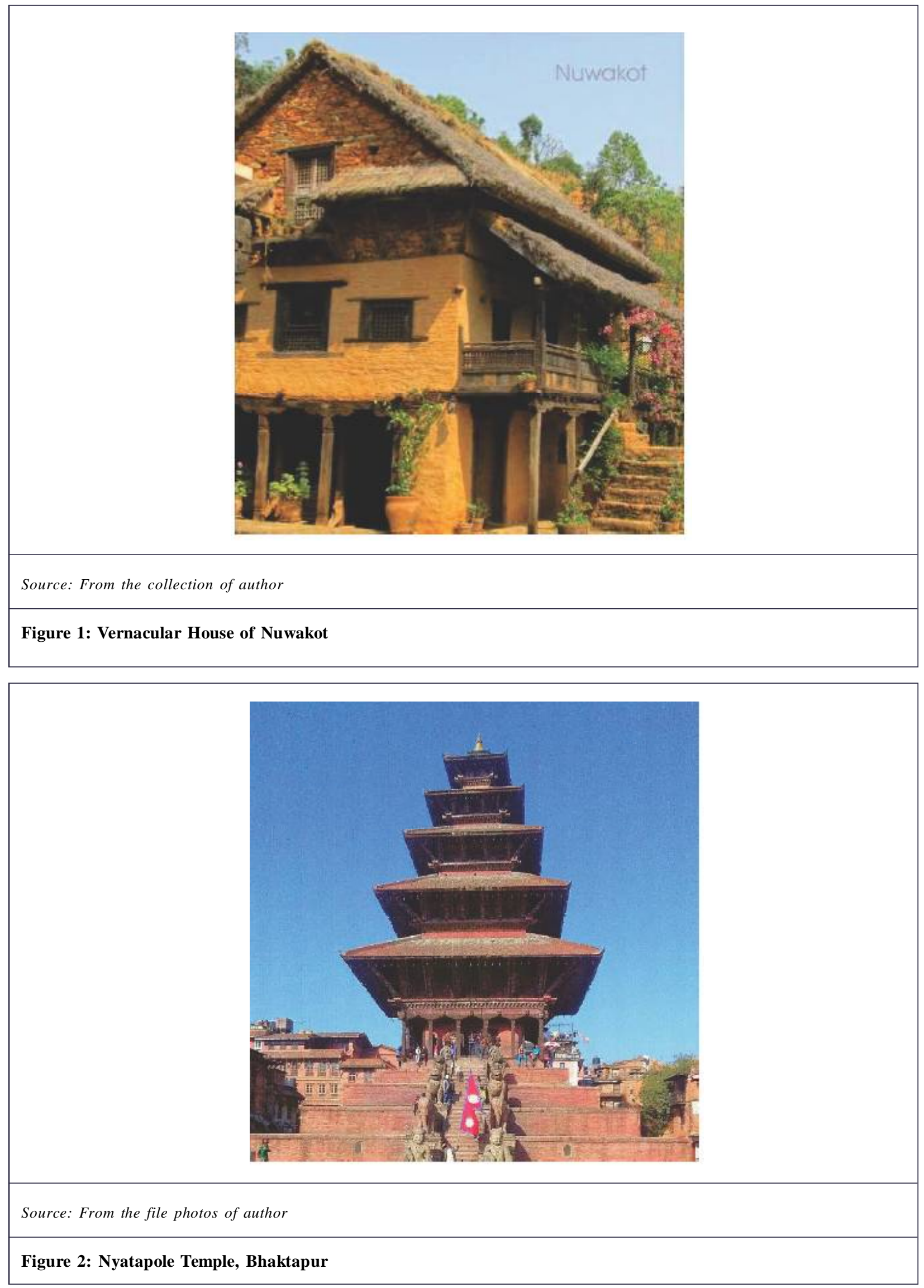


\section{Conclusion}

A country is not only identified by its people and government, but by its architecture. "Through architecture it's possible to gauge many things about a culture, such as lifestyle, artistic sensibilities and social structure" (Damen, 2007). For example, when one thinks of Nepal, we think of the Malla period. Without their culture, would the temple architecture of that time be designed and developed in that way?? The Egyptians are another amazing example, their environment and culture produced the great pyramids. How do modern cultures produce and maintain such beautiful architecture???

\section{Acknowledgment}

I would like to acknowledge and extend my heartfelt gratitude to the course tutor and my mentor Dr. Kishan Datta Bhatta for his constant guidance monitoring and encouragement throughout the course of this research and the preparation of an article. I would further like to thank my fellow classmates for helping and providing me the necessary help and information.

\section{References}

Ahianba, J.E. (2009). Cultural Issues in Architecture, Case study of Esan in Nigeria.

Damen, M. (2007). USU1320 - History and Civilization, Fall, 2007. University Studies - OCW. Course 2.

Edwards Paul. Ed. (1967). The Encyclopedia of Philosophy, New York: The Macmillan Company and The Free Press.

Geertz, C. (1957). American Anthropologist.

Joanna, T. (2014). Managing Editor, Oxford Advanced Learner's Dictionary, New 8th Edition, Oxford University Press.

Moore, G.T. (n.d.). "Environment-Behaviour Studies", in Introduction to Architecture, New York: Mc.Graw-Hill

Neilson, W. A. (1941). Ph.D., Chief Editor, Webster's New International Dictionary of the English Language, Second Edition, Unabridged Springfield, Massachusetts: G \& C Merriam Company, 1941.

Rapoport, A. (1969). House, Form and Culture, New Jersey, Precentice Halls.

Citethis articleas: Saurav Koirala(2021). Cultural Context in A rchitecture. International Journal of A rchitecture and Planning. 1(2), 23-27. doi: 10.51483/ IJA RP.1.2.2021.23-27. 